\title{
Optimizing the Performance of an Automatic Clamping System for Gear-Shaping Machines
}

\author{
Dr.C.Nithyanandam1 ${ }^{1}$, R.Gowtham ${ }^{2}$, M.Muthupandiaraja ${ }^{3}$ \\ ${ }^{1}$ Associate Professor in Mechanical Engineering, Hindusthan College of Engineering and Technology, Coimbatore, \\ .$^{2}$ Student in Final Year M.E.(CAD/CAM), Hindusthan College of Engineering and Technology, Coimbatore \\ ${ }^{3}$ Student in Final Year M.E.(CAD/CAM), Hindusthan College of Engineering and Technology, Coimbatore
} ****.

Abstract - Gear shaping machine is used to manufacture both external and internal gears. It is a semi-automatic controlled machine in which all machining operations are carried out by automatically indexing, where loading and unloading of a work piece are performed manually. Also, the operator needs to wait for unloading, until the entire machining operation to be completed. Hence manufacturing cost is increased due to labor charges and overall machining time. Our proposed technique is to minimize the total cost of manufacturing, it is planned to eliminate the manual operation in loading and unloading of each component. Full automation of shaping machine requires storing device, a transfer device, automatic clamp device, and sequence controlling system. Full automation of shaping machine requires storing device, a transfer device, automatic clamp device, and sequence controlling system. The objective of this paperwork is to design a pneumatic clamping device needed for an automatic loading system, to hold the work piece the revolving table using Pro-E Wildfire software. Then calculate the clamping force theoretically for various pressure ranges and find the suitable working pressure. Also, static analysis of all designed components is performed to validate their strength using Ansys software. Based on the dimension, all parts are manufactured and assembled to test their performance.

Key Words: Automatic loading system, Automatic clamping system, Controlling system, Design, Mechanism Simulation.

\section{INTRODUCTION}

Now a days, all industries are interested to convert their conventional machine to fully automatic machines, to make their industries fully automatic control. A fully automatic control System helps to overcome the labor shortage and minimize the time of production by decreasing the cost of production. A shaping machine is used to manufacture both internal gear and external gear. It is a semiautomatic control machine. It can perform all machining operations (speed, feed, and depth) and controlling systems (indexing to next cycle, lubrication system on off, controlling sequence of operation) by itself.

\section{SEMI-AUTOMATIC GEAR SHAPING MACHINE}

\section{A. Gear shaping machine}

It is a semi-automatic machine. It consists of slider crank mechanism to provide reciprocating motion of tool and
Indexing mechanism to give proper feed and depth while machining. Rotary table with manual collet is used to hold the component while machining.

At the first occurrence of an acronym, spell it out followed by the acronym in parentheses, e.g., Charge -coupled Diode (CCD).

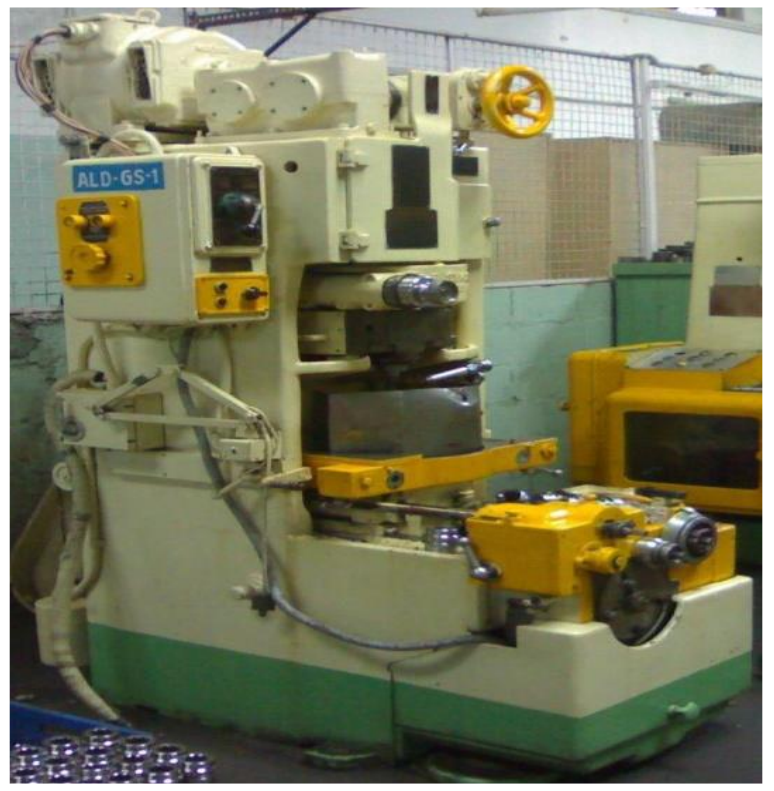

Fig. 1 Gear Shaping Machine

B. Spline coupling

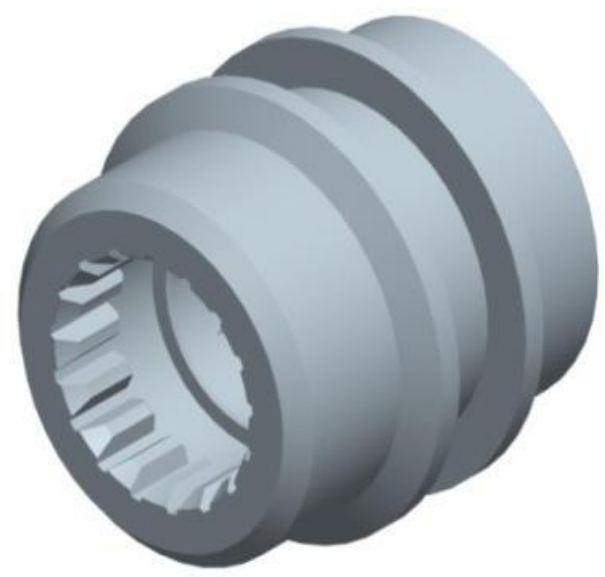

Fig. 2 Spline Coupling

Spline coupling consists of 17 gear teeth (internal) and 8 keyways (internal). It is made up of $20 \mathrm{MnCr} 5$ alloy material (58 to $62 \mathrm{HRC}$ ). Spline coupling is a unit device used in the 
gearbox of Tata Motors, Ashok Leyland, and Eicher Motor vehicles. In spline coupling number of machining operations are performed such as facing, step turning, boring, chambering, slotting, internal gear cutting, etc. Among all operations, the final and critical operation is internal gear cutting.

C. Available space for locate the clamp.

i. Dimension of the rotary table Diameter $=280 \mathrm{~mm}$

No of $T$ slot $=6$ no's

Bore Dia. $=56.7 \mathrm{~mm}$

ii. Maximum distance between table $\&$ tool $=124 \mathrm{~mm}$

iii. Minimum distance between table $\&$ tool $=90 \mathrm{~mm}$

\section{DESIGNING OF CLAMP}

\section{A. Pneumatic clamp}

It is an expanding collet-type pneumatic clamp. It consists of a cylinder \& piston arrangement, collet, retraction spring, and a bush. Clamp is fixed on the rotation table by means of bolt and nut. Working fluid (pressured air) was supplied to the cylinder though bush and Quick coupler arrangement.

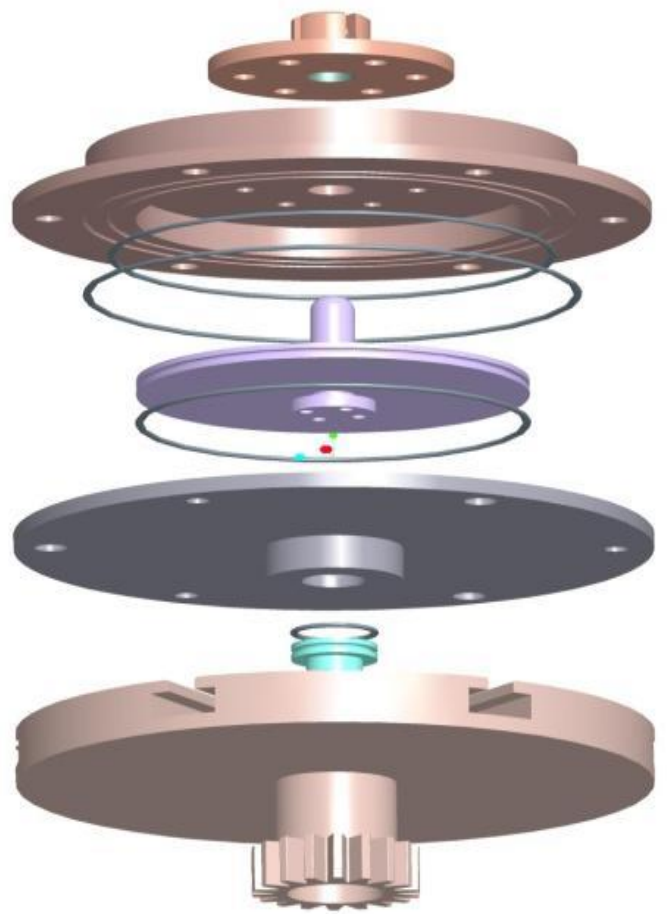

Fig. 3 Clamp Parts

\section{B. Working Principle.}

Pressured air from the direction control valve reaches the camping cylinder through the base plate bush. Due to high-pressure air, the piston gets pushed up and expands the four jaws, and holds the work piece tightly. For de-clamping, the direction control valve changes its position and cuts the supply of pressurized air. Then retraction spring pushes back the piston downward to its initial position. They are by expanding jaws get a contract and release the work piece. Thus the automatic clamp holds the work piece after machining on the rotating tablelwhile the machine and releases the clamp.

\section{Clamp Casing}

Table I Selection of Materials

\begin{tabular}{|c|l|l|c|}
\hline S. No & Components & Material & Poisson's ratio \\
\hline 1 & Clamp casing & Mild steel & 0.3 \\
\hline 2 & Clamp base plate & Mild steel & 0.3 \\
\hline 3 & Piston plate & 20MncR5 & 0.3 \\
\hline 4 & Collet & EN31 & 0.3 \\
\hline 5 & Base plate bush & Pb2 & 0.3 \\
\hline 6 & 'O' Ring & Rubber & 0.48 \\
\hline 7 & Disc spring & Spring Steel & 0.3 \\
\hline
\end{tabular}

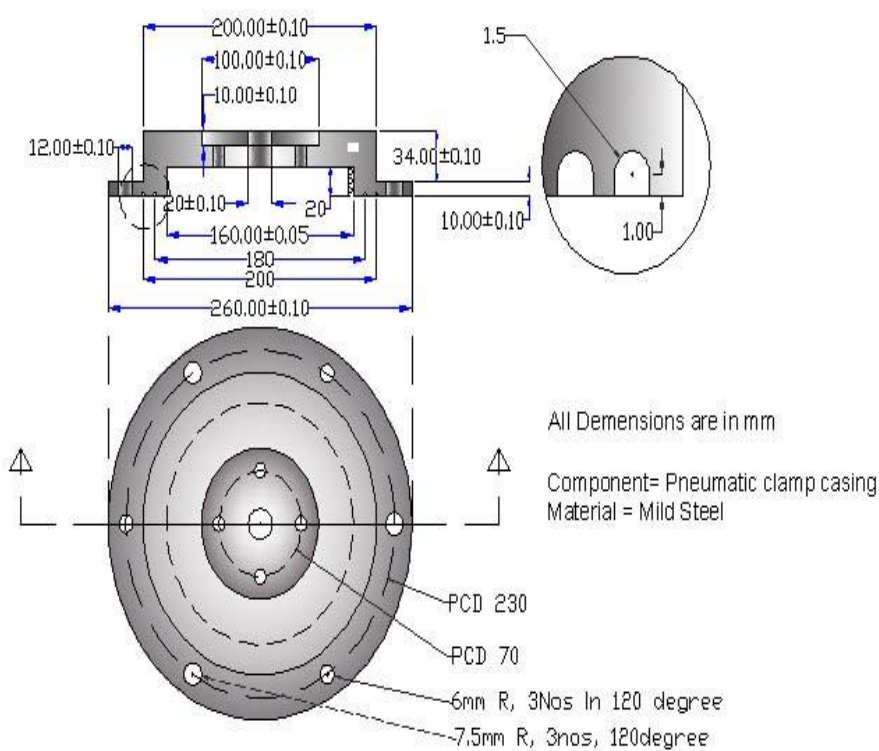

Fig. 4 Clamp Casing

The clamp casing is made of mild steel. It consists of six-hole provided at the PCD of 230mm which helps to mount the clamp on the table. Piston slide in the $160 \mathrm{~mm}$ bore freely. The grinding operation was made at the $160 \mathrm{~mm}$ bore to maintain 0.05 tolerances. On the other side of the casing, a $100 \mathrm{~mm}$ dia. bore was provided to fix the collet. Two grooves of $2.5 \mathrm{~mm}$ depth with PCD $(200 \mathrm{~mm}$ and $180 \mathrm{~mm})$ are used to provide to fix the $\mathrm{O}$. These two $\mathrm{O}$ rings, prevent the leakage of air between the clamp casing and base plate. 


\section{Clamp Base Plate}

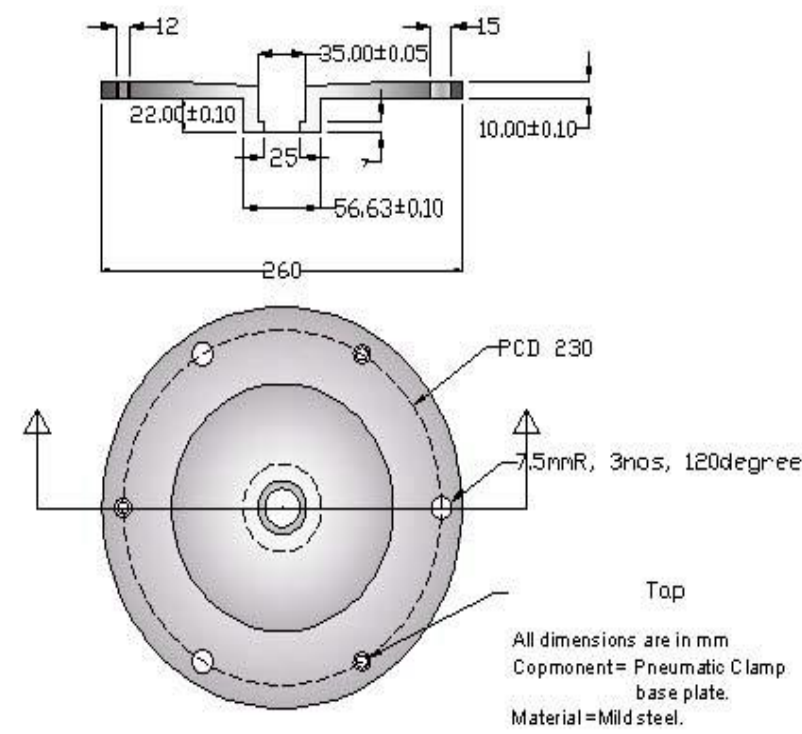

Fig.5 - Clamp Base Plate

It consists of a bore $35 \mathrm{~mm}$ diameter and $25 \mathrm{~mm}$ depth. A bush with $33 \mathrm{~mm}$ ' $\mathrm{O}$ ' ring was provided at the bore. Base plate helps to transmit the pressurized air to the rotating clamp without any leakage. $2 \mathrm{~mm}$ taper provided at the top of the base plate which helps to allow the pressurized air to entire bottom surface of the piston.

\section{E. Clamp Piston}

Piston is made of $20 \mathrm{MnCr} 5$ material. It consists of $160 \mathrm{~mm}$ diameter plate with $10 \mathrm{~mm}$ thickness and $35 \mathrm{~mm}$ rod with $77 \mathrm{~mm}$ length which are welded together.

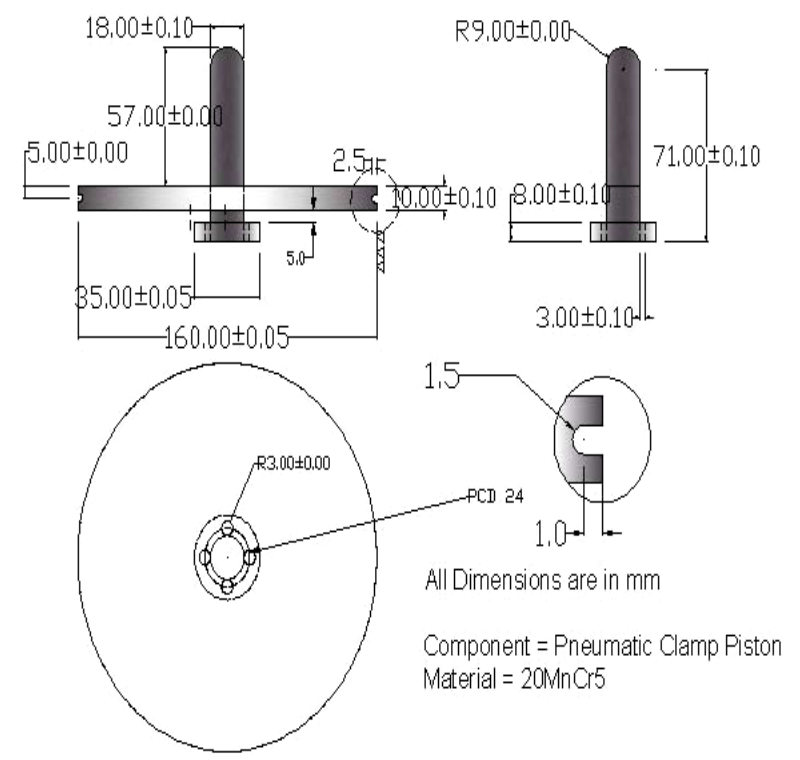

Fig.6 - Clamp Piston

The four holes with $5 \mathrm{~mm}$ diameter and $5 \mathrm{~mm}$ gap provided at the bottom to transmit the pressurized air to entire bottom surface of the piston. A groove of $3 \mathrm{~mm}$ diameter provided at the piston plate to fix the $180 \mathrm{~mm}$ diameter ' $\mathrm{O}$ ' ring. Arrangement provided at base of piston rod helps to guide the piston along vertical movement.

\section{F .Clamp Collet}

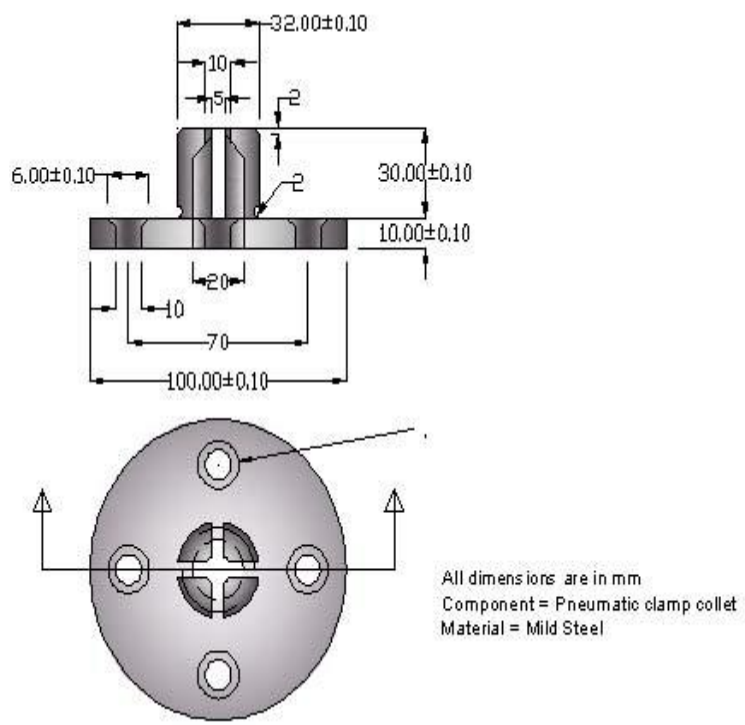

Fig. 7 - Clamp Collet

Clamp collet is made of EN31 material. EN31 material is a low carbon steel hence it is more elastic nature [8]. It consists of four flexible Jaws which are used for hold the work piece. Four tapered holes are provided to fix the collet on the clamp casing tightly.

\section{G. Base Plate Bush}

Clamp base plate bush is made of $\mathrm{Pb} 2$ material. $\mathrm{Pb} 2$ material have low coefficient friction hence it can reduce wear of material due frictional [8]. The groove provided at the bush helps to fix the $33 \mathrm{~mm}$ dia ' $O$ ' ring. $O$ ' ring prevent the leakage of the pressurized air through the base plate.

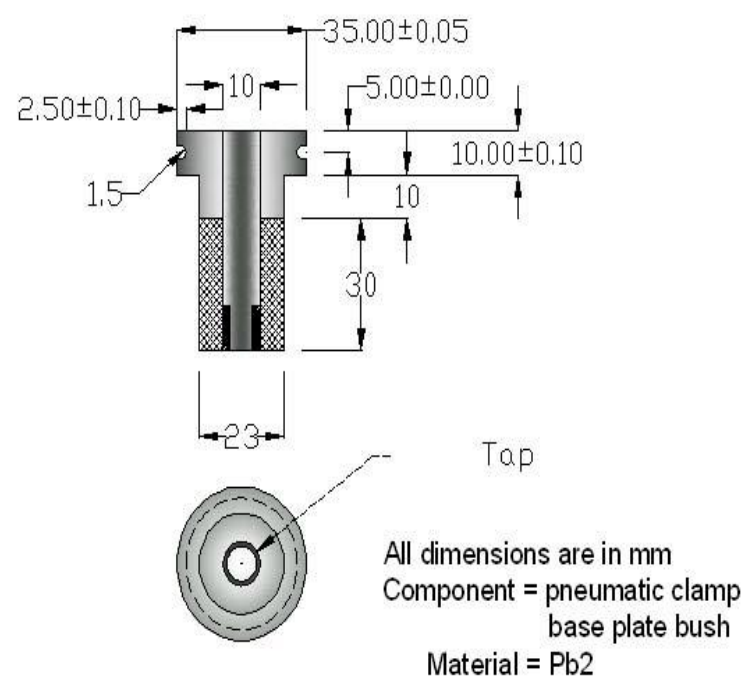

Fig.8 - Base Plate Bush

\section{H. Retraction Spring}

Space between the piston (rod side) and casing is very small $(12 \mathrm{~mm})$, hence a disc type spring of $100 \mathrm{~mm}$ outer diameter and $25 \mathrm{~mm}$ inner diameter is used to retract the piston back ward for de-clamping. 


\section{FORCE CALCULATION}

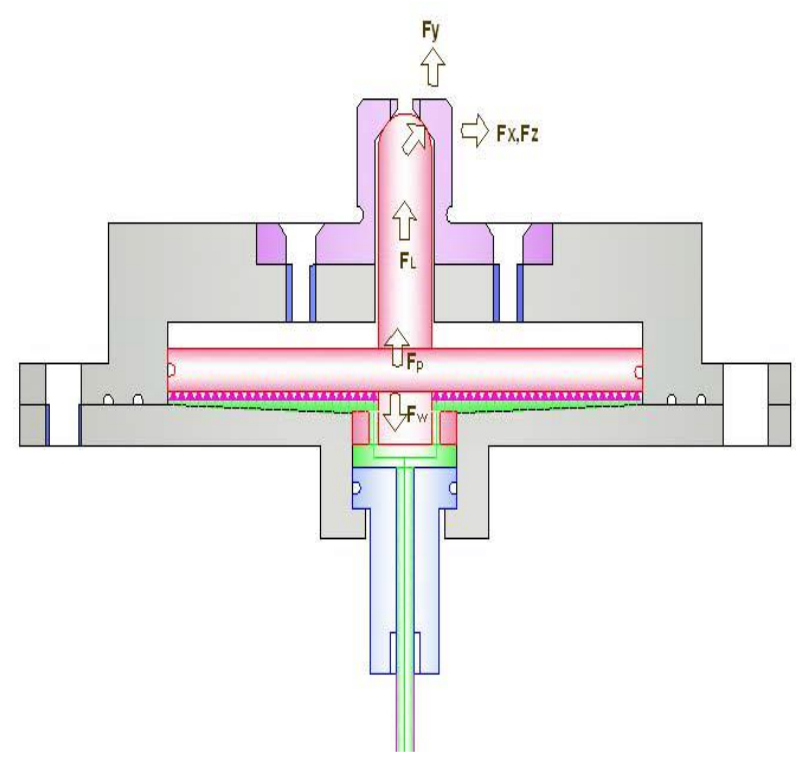

Fig.9 Direction of Forces

$\mathrm{Fp}=$ Force developed by pneumatic pressure

$\mathrm{Fw}=$ Weight of the piston

$\mathrm{FL}=$ Net lifting force

$\mathrm{Fj}=$ Force act on single jaw

$\mathrm{FF}=$ Force required to overcome friction

$\mathrm{FS}=$ Force required to overcome spring force

$\mathrm{FE}=$ Force required to expand all spring

$\mathrm{Fx}, \mathrm{Fy}, \mathrm{Fz}=$ Force acting along $\mathrm{X}, \mathrm{Y}$ and $\mathrm{Z}$ axis

$\mathrm{Fx}+\mathrm{Fz}=$ clamping force

Compressor output $=0-10$ bar.

Operating pressure range $=3-8$ bar.

Area of piston $=\pi \mathrm{d}^{2} / 4=3.14 \times 160^{2} / 4$ $=20106.192 \mathrm{~mm}^{2}$

Force developed in piston $\mathrm{F}_{\mathrm{p}}=$ Pressure $\times$ Area

Weight of the piston $\mathrm{Fw}=2 \mathrm{Kg}$

Net lifting force developed $\mathrm{F}_{\mathrm{L}}=\mathrm{F}_{\mathrm{p}}-\left(\mathrm{F}_{\mathrm{w}}+\mathrm{FF}_{\mathrm{F}}+\mathrm{Fs}_{\mathrm{s}}+\mathrm{F}_{\mathrm{E}}\right) \quad$ Eq.1

Total no of jaws $=4$

Force shared to single jaw $F_{j}=F_{L} / 4$

Eq. 2

Force acting along $\mathrm{X}$ axis $=\mathrm{F}_{\mathrm{j}} / 4$

Force acting along $\mathrm{Y}$ axis $=\mathrm{F}_{\mathrm{j}} / 2$

Force acting along $\mathrm{Z}$ axis $=\mathrm{F}_{\mathrm{j}} / 4 \mathrm{Eq} .5$

TABLE II Calculation of Clamping Force

\begin{tabular}{|c|c|c|c|c|c|c|}
\hline 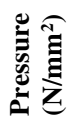 & 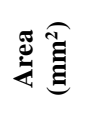 & 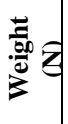 & 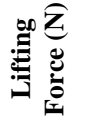 & 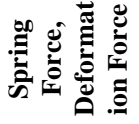 & 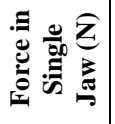 & 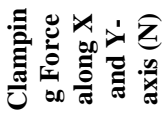 \\
\hline $\mathbf{A}$ & B & $\mathbf{C}$ & $\begin{array}{c}D= \\
(A * B) \\
-C\end{array}$ & $\mathbf{E}$ & $\begin{array}{c}\mathrm{F}=(\mathrm{C}- \\
\mathrm{E}) / 4\end{array}$ & $\mathbf{G}=\mathbf{F} / 2$ \\
\hline 0.3 & 20106 & 20 & 6012 & 2010 & 1000 & 500 \\
\hline 0.4 & 20106 & 20 & 8022 & 2010 & 1503 & 750 \\
\hline 0.5 & 20106 & 20 & 10033 & 2010 & 2005 & 1000 \\
\hline 0.6 & 20106 & 20 & 12043 & 2010 & 2508 & 1250 \\
\hline 0.7 & 20106 & 20 & 14054 & 2010 & 3011 & 1500 \\
\hline 0.8 & 20106 & 20 & 16064 & 2010 & 3513 & 1750 \\
\hline
\end{tabular}

\section{RESULT AND DISCUSSIONS}

\section{A. Expansion}

By using ANSYS software, the development of all jaws designed for different sort of pressure are determined and tabulated. Force developed by pressurized air is equally circulated to all jaws and also helps to increase the jaws outer to embrace the work piece strongly.

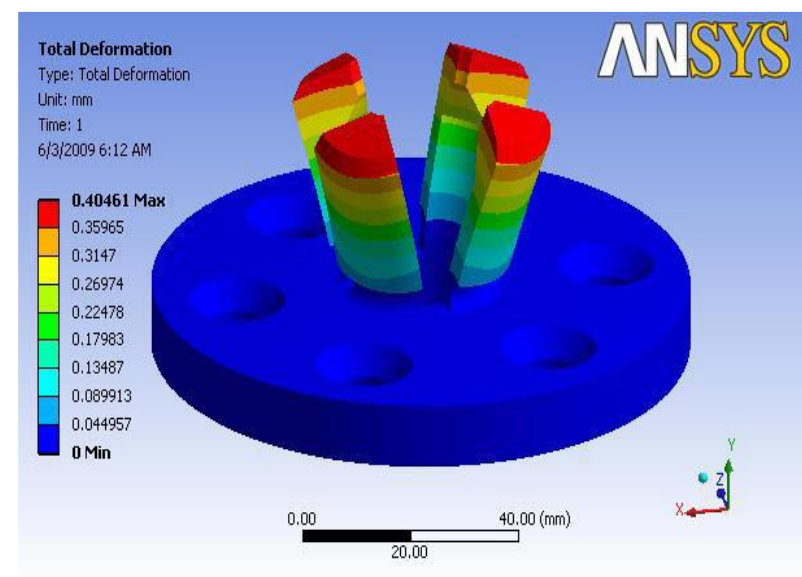

Fig. 10 - Expansion of Collet

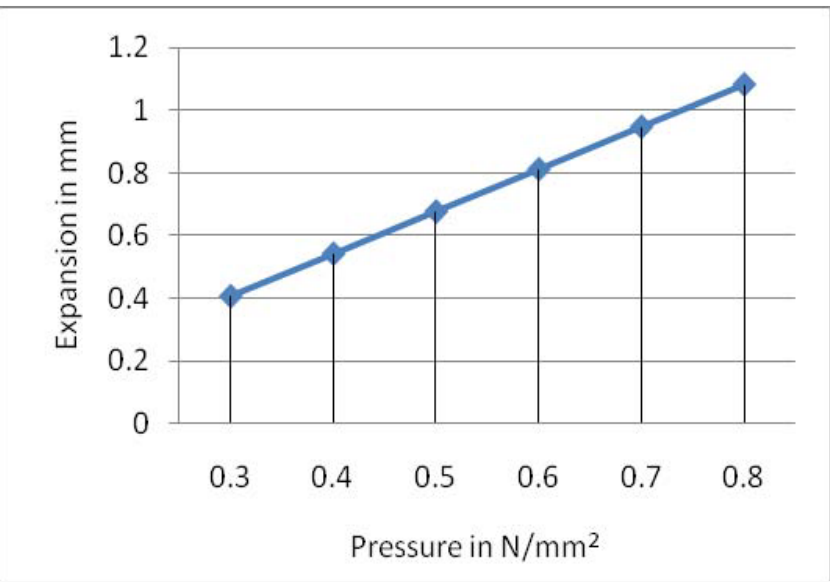

Fig.11 Expansion of Jaw Based on Applied Pressure

\section{A. Equivalent Stress}

Each jaws in collet perform as a simply supported beam. While expansion maximum stress formed at the base of each jaws. Here, ANSYS software comparable stresses at various parts of jaws for dissimilar pressure series are considered and tabulated. 


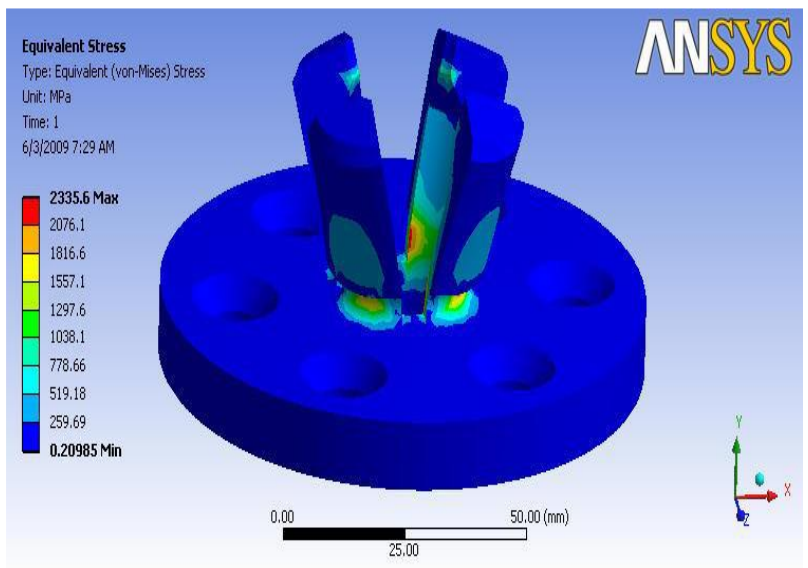

Fig.12 Equivalent Stress at 8 bar Pressure

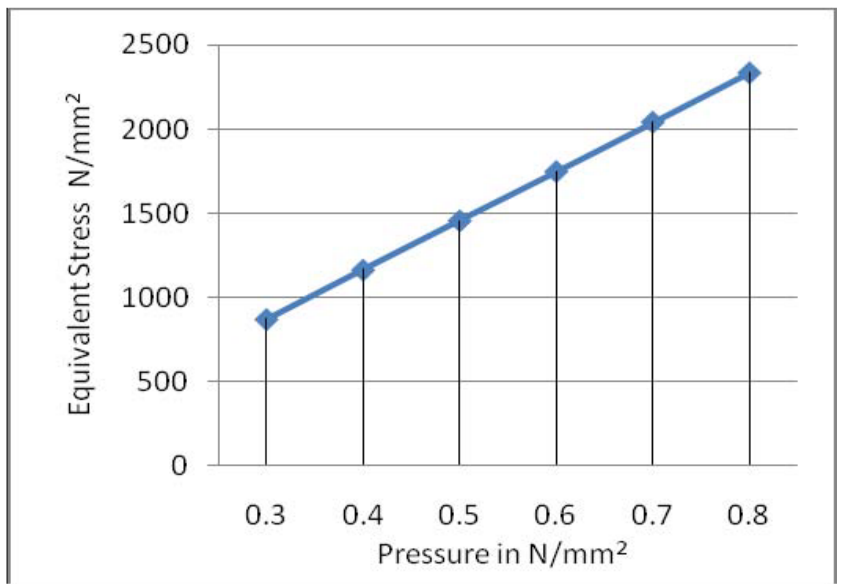

Fig.13 Stress Formation Based on Applied Pressure

\section{B. Assembling of Pneumatic Clamp}

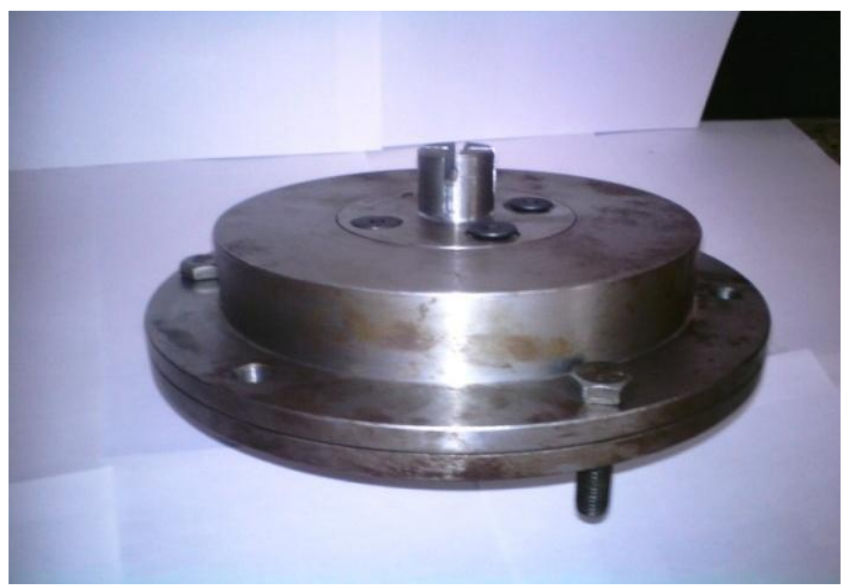

Fig. 14 - Assembled Clamp

\section{CONCLUSIONS}

A pneumatic clamp was designed to clamp the work piece on the revolving table while machining. It consists of a cylinder piston with increasing collets deal at its end. Force acting on every jaw due to pneumatic pressure was considered tentatively. Then the total deformation $\&$ the same stress are determined using ANSYS software. Based on the deformation and stress creation, suitable dimension and materials for every parts of clamp are preferred. Lastly, all parts for the pneumatic clamp were manufactured and its performance was tested. From the result it was fulfilled that about $50 \%$ of developed force is utilized by the retraction spring and mounting jaws, remaining $50 \%$ of force is utilized for clamping of work piece.

Future work is to eradicate retraction spring by converting single acting actuator type clamp into double acting type and also introducing pivoted type jaw instead of fixed type jaw, so obtaining $90 \%$ clamp success.

\section{REFERENCES}

1. Ninad Male, Prerit Shah, Tanveet Marucha, Parth Mullaji: Automated Pneumatic Fixture, International Journal of Advance Research, Ideas and Innovations in Technology, 6 (2), 2020.

2. Himanshu Vasnani, Dr. Neeraj Kumar: A Review on Gear Hobbing Process, International Journal for Research in Engineering Application \& Management (IJREAM), 04 (11), 2019.

3. Jaykumar K Dhulia and Dr. Nirav P Maniar: Design, Modeling and Manufacturing of 16 Cylinder Hydraulic Fixture with Automated Clamping System, IOP Conf. Series: Journal of Physics: Conf. Series 1240 (012036), 2019.

4. Miroslav Císar, Ivan Kuric, Nadežda Čuboňová, and Matej Kandera: Design of the clamping system for the CNC machine tool, MATEC Web of Conferences 137(01003), 2017.

5. Sanket.R.Dehade, Rahul Rasal, Sanket.H.Hingankar: Literature Review on Gear Deburring System, International Research Journal of Engineering and Technology (IRJET), 04 (05), 2017.

6. G.Leela Prasad, N.Niranjan, J.Vikram; An Experimental Study on the Transmission Gear Tooth Run out, American Journal of Engineering Science and Research, 2015.

7. R. Singla, Sushil Kumar: An Intelligent Clamping System for Drilling Operation - A Review, SSRG International Journal of Mechanical Engineering, http://www.ijettjournal.org/

8. Navya K.R.1, S. Pradeep: Automation of Fixtures Using Hydraulic Power Pack for a Bogie Under frame, IOSR Journal of Mechanical and Civil Engineering, 10(1), 2013.

9. Amar Raj Singh Suri, A.P.S. Sethi: Development of Gear Hobbing Fixture Design for Reduction in Machine Setting Time, International Journal of Scientific and Research Publications, 2(10), 2012.

10. S. S. Ngu, L. C. Kho, T. P. Tan \& M. S. Osman: Design of the Roller Clamp Robotic Assembly, World Academy of Science, Engineering and Technology, 68(1), 2012. 